\title{
Down-regulation of p21-activated serine/ threonine kinase 1 is involved in loss of mesencephalic dopamine neurons
}

\author{
Hwanhee Kim¹, Jun-Young Oh', Sun-Lim Choi', Yeon-Ju Nam¹, Anna Jo', Ara Kwon', Eun-Young Shin², \\ Eung-Gook Kim² and Hyong Kyu Kim ${ }^{1,3^{*}}$
}

\begin{abstract}
Background: Although the roles of p21-activated serine/threonine kinase 1 (PAK1) have been reported in some neurodegenerative diseases, details regarding neurodegeneration are still limited. Hence, we tried to determine the role of PAK1 and molecular mechanisms of neuronal death involved in neurodegeneration.

Results: Expression of a dominant-negative form of PAK1 (PAK1 ${ }^{\mathrm{H} 83,86 \mathrm{~L}, \mathrm{~K} 299 \mathrm{R}}$, PAK1-DN) decreased the cell viability and increased cell death induced by oxidative stress. Indeed, oxidative stress decreased the phosphorylation of PAK1 in neuroblastoma cells, cultured dopamine (DA) neurons, or rat midbrains. PAK1-DN reduced the level of Bcl-2 protein, through an ubiquitin/proteasome-dependent mechanism. The level of $\mathrm{BCl}-2$ may be regulated by PAK1-ERK signaling and/or PAK1, directly. Conversely, expression of an active form of PAK1 (PAK1 ${ }^{T 423 E}$, PAK1-CA) could recover both loss of DA neurons in the substantia nigra (SN) and behavioral defects in a 6-OHDA-induced hemiparkinsonian rat model.

Conclusions: Our data suggest that the oxidative stress-induced down-regulation of PAK1 activity could be involved in the loss of mesencephalic DA neurons through modulation of neuronal death, suggesting a novel role of PAK1 as a molecular determinant and mechanisms in the pathogenesis of Parkinson's disease.
\end{abstract}

Keywords: PAK1, BCl-2, Apoptosis, Neurodegeneration, Parkinson's disease

\section{Background}

The p21-activated serine/threonine kinase 1 (PAK1) has a role in a variety of cellular functions like cell motility, cell cycle, survival, and even death. In cancer cells, PAK has functional roles in growth, invasion, and metastasis [1-5]. Accordingly, the activity of PAK1 is up-regulated through protein overexpression or gene amplification in cancer tissues $[4,5]$. Although the roles of PAK1 have been widely studied in a variety of cancers and cancer cells, other roles of PAK1 still remain to be elucidated [6].

\footnotetext{
*Correspondence: hkkim69@chungbuk.ac.kr

'Department of Medicine and Microbiology, College of Medicine, Signaling Disorder Research Center, Chungbuk National University, Cheongju 28644, The Republic of Korea

${ }^{3}$ Department of Medicine and Microbiology, College of Medicine, Chungbuk National University, Chungdae-ro 1, Seowon-gu, Cheongju 28644, The Republic of Korea

Full list of author information is available at the end of the article
}

Tumor formation and progression requires changes in cellular events such as the expression of oncogenes, activation of anti-apoptotic signaling pathways, and simultaneous inactivation of pro-apoptotic signals as well as of tumor suppressors. Apoptosis (type I cell death), also known as programmed cell death, is a finely regulated mechanism initiated by signaling in response to a variety of stresses cells. Thus, it has important roles in development and tissue homeostasis in multicellular organisms. The susceptibility to apoptotic cell death is dependent on the relative level of anti-apoptotic proteins of $\mathrm{Bcl}-2$ family members (Bcl-2, Bcl- $\left.\mathrm{x}_{\mathrm{L}}, \mathrm{Mcl}-1\right)$ to that of proapoptotic proteins of the family (Bad, Bax, Bak, Bok) or the interaction of each protein. Anti-apoptotic protein $\mathrm{Bcl}-2$, which acts as a proto-oncogene, is a member of protective complexes that help to maintain the integrity of mitochondrial membrane. Pro-apoptotic proteins, such as Bad and Bax, can bind to Bcl-2. This binding 
inhibits the function of $\mathrm{Bcl}-2$ and induces the release of pro-apoptotic factors by neutralizing the effects of proapoptotic proteins, and cell death eventually [7-9]. PAK1 affects the activity of pro-apoptotic signals in a Raf-1 dependent or independent manner. Raf-1 activated by PAK1 is translocalized to the mitochondria, and then it phosphorylates Bad, which is a pro-apoptotic protein [10]. Alternatively, PAK1 directly phosphorylates Bad on Ser112 and Ser136, inducing inhibition of the interaction with $\mathrm{Bcl}-2$ or $\mathrm{Bcl}-\mathrm{x}_{\mathrm{L}}$ and subsequently resulting in cell survival [11].

In the nervous system, dysregulation of PAK signaling is implicated in neurodegenerative diseases, such as Alzheimer's disease (AD) and Huntington's disease (HD), and mental retardation [12]. Down-regulation of PAK1 and PAK3, brain specific forms, has been reported in AD brain [13]. Also, PAK1 overexpression enhanced the toxicity in a HD cellular model [14]. Rac-PAK signaling was found to be defective in the mouse model of Fragile $\mathrm{X}$ syndrome, Fmr1-KO mouse, suggesting that PAK1 might also be involved in the pathogenesis of mental retardation [15]. In addition, knockout of PAK1 induced defects in brain development [16]. However, up to now, molecular details involved in Parkinson's disease (PD) are limited.

It has been widely thought that cancer or neurodegenerative disease may originate from opposite fate of cells, to death or persistent growth, respectively. As a matter of fact, some neurodegenerative diseases, such as PD, have an evident inverse co-morbidity with many cancers [17]. A certain protein, known as a genetic determinant, may decide directions of the disease to either cancers or neurodegenerative diseases according to the cellular condition in which the determinant is activated or inactivated, or the cell type, whether or not the cells have the ability to proliferate in response to the same external stimuli that can induce DNA damage or cell cycle activation [18]. Even importance of genetic determinants or molecular determinants in the pathogenesis of such diseases, not much research has been performed.

The contradictory roles of PAK1 in cancers and AD and in cell survival and cell death suggest the possibility of PAK as a new molecular determinant whose activity could determine cell fate. Hence, we examined the role of PAK1 in neuronal death. Here, we report novel molecular mechanisms involved in the death of mesencephalic DA neurons mediated by PAK1 and suggest a new molecular target for a therapeutic agent in PD.

\section{Results}

Down-regulation of PAK1 activity increases apoptotic cell death

In order to determine the role of PAK1 in cell proliferation and viability, we constructed the cell lines stably expressing wild-type PAK1 (WT), constitutively active PAK1 mutant (PAK1-CA, PAK1 ${ }^{\mathrm{T} 423 \mathrm{E}}$ ), dominantnegative PAK1 mutant (PAK1-DN, PAK1 ${ }^{\mathrm{H} 83,86 \mathrm{~L}, \mathrm{~K} 299 \mathrm{R}}$ ) $[19,20]$, or GFP using a neuroblastoma cell line, SHSY5Y cell line, lentiviral vector, and fluorescenceactivated cell sorting. The SH-SY5Y cells strongly expressed endogenous PAK1 (Additional 1: Figure S1). First, to examine the viability of each cell line, the same number of cells ( $1 \times 10^{5}$ cells) were plated and incubated for $72 \mathrm{~h}$ and the amount of viable cells was measured. As expected, the expression of PAK1-CA increased the cell viability to $35 \%$, but the expression of PAK1-DN decreased the cell viability to $35 \%$ compared to that of GFP-expressing cells (Fig. 1a). In addition, these effects were recapitulated when cell death was induced by oxidative stress, such as treatment with hydrogen peroxide $\left(\mathrm{H}_{2} \mathrm{O}_{2}\right)$ or 6-hydroxydopamine (6-OHDA) (Fig. 1b, c). These data indicate that down-regulation of PAK1 activity enhances both cell death and vulnerability to oxidative stress. Subsequently, we examined the cell death mechanism which might be involved in the decrease of cell viability induced by PAK1-DN expression. At $72 \mathrm{~h}$ after plating, SH-SY5Y cells expressing PAK1 mutants were subjected to TUNEL staining. Apoptotic cell death in PAK1-DN-expressing cells was increased by approximately $118 \%$, compared to that in GFP-expressing control cells. On the contrary, apoptotic cell death in PAK1CA expressing cells was decreased compared to that in the control cells, but the difference was not significant. These results indicate that PAK1 activity could regulate apoptotic cell death in neuroblastoma cells.

\section{PAK1 is inactivated by oxidative stress}

Oxidative stress induces cell death, either necrosis (type 2 cell death) or apoptosis (type 1 cell death), in a variety of cells. In our experiments, PAK1-DN expression increased cell death induced by treatment with $\mathrm{H}_{2} \mathrm{O}_{2}$ or 6hydroxydopamine (6-OHDA), but PAK1-CA expression decreased cell death (Fig. 1b, c). Hence, we examined whether oxidative stress can regulate the activity of PAK1. In order to address this question, we examined the relative level of phosphorylated PAK1 (p-PAK1) to that of total PAK1 induced by $50 \mu \mathrm{M}$ 6-OHDA treatment in SH-SY5Y cells at several time points. The 9 h-treatment with 6OHDA significantly decreased the value of p-PAK1/PAK1 and this reduction was correlated with the reduction in the of Bcl-2 level (Fig. 2a, b). In addition, the reduction in the Bcl-2 level was also dependent on post-transcriptional mechanisms (Additional file 2: Figure S2). The inactivation of PAK1 by oxidative stress, such as 6-OHDA treatment, was further examined in an animal model. At one week after $20 \mu \mathrm{g}$ of 6-OHDA was infused into the striatum of rats, the midbrain regions were isolated and subjected to Western blot analysis for p-PAK1 and PAK1. 

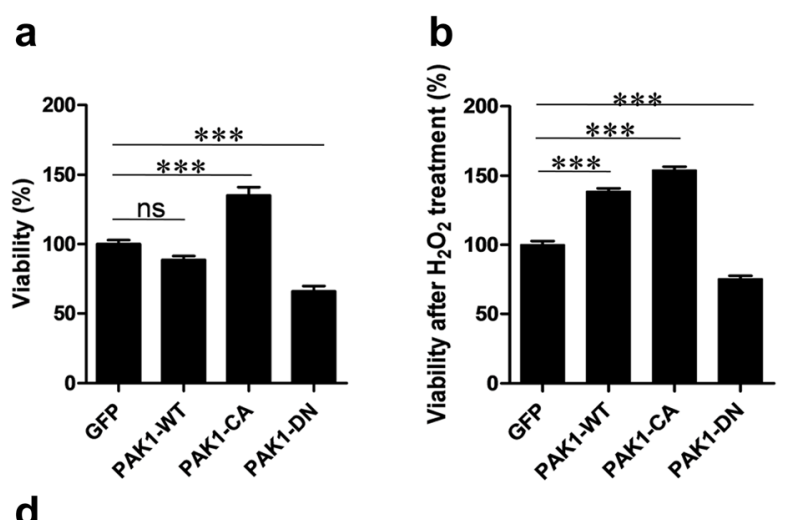

d
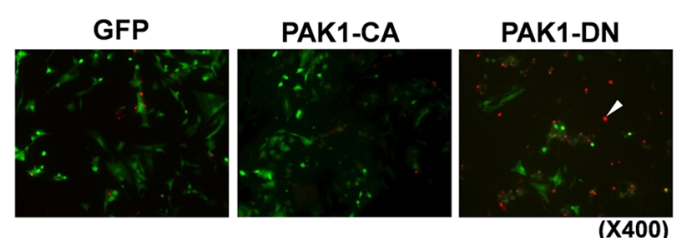
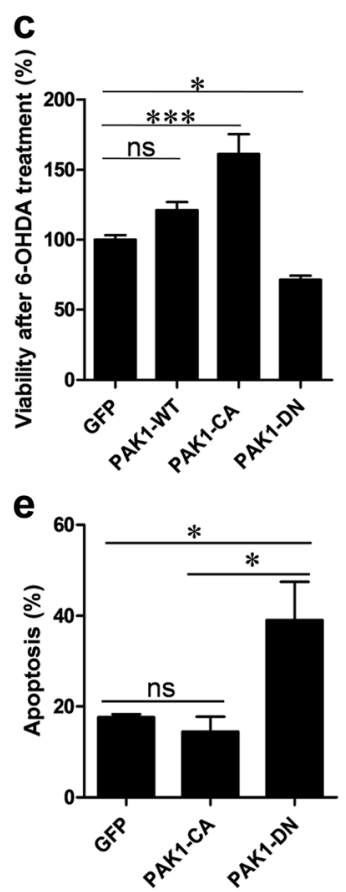

Fig. 1 PAK1-DN expression reduces viability. a PAK1-DN expression reduced viability of SH-SY5Y cells but expression of PAK1-CA mutant increased viability of Sh-SY5Y cells (GFP: $100.0 \pm 2.99 \%, n=4$; WT: $88.6 \pm 2.84 \%, n=4$; CA: $135.1 \pm 6.03 \%, n=4$; DN: $65.94 \pm 3.80 \%, n=4$; One-way ANOVA, $F_{3,15}=$ $49.14,{ }^{* * * * *} P<0.0001$, Newman-Keuls multiple comparison test: ${ }^{* * *} P<0.001$, ns: not significant). b PAK1-DN expression reduced viability of SH-SY5Y cells after oxidative stress induced by treatment with hydrogen peroxide (GFP: $100.0 \pm 2.68 \%, n=12$; WT: $138.7 \pm 2.13 \%, n=12 ;$ CA: $154.1 \pm 2.52 \%, n=12$; DN: $75.41 \pm 2.18 \%, n=12$; One-way ANOVA, $F_{3,47}=225.6,{ }^{* * * * *} P<0.0001$, Newman-Keuls multiple comparison test: $\left.{ }^{* * * *} P<0.001\right)$. c PAK1-DN expression reduced viability of SH-SY5Y cells after oxidative stress induced by treatment with 6-hydroxydopamine (GFP: $100.0 \pm 3.12 \%, n=4$; WT: $121.2 \pm 5.73 \%, n=4$; CA: $161.3 \pm 14.11 \%, n=4 ; \mathrm{DN}: 71.35 \pm 2.92 \%, n=12$; One-way ANOVA, $F_{3.15}=22.95,{ }^{* * * *} P<0.0001$, Newman-Keuls multiple comparison test: ${ }^{*} P<0.05$,

${ }^{* * * *} \mathrm{P}<0.001$, ns: not significant). d PAK1-DN expression significantly increased apoptotic cell death. At $72 \mathrm{~h}$ after plating of SH-SY5Y cells expressing PAK1 mutants, the cells were subjected to TUNEL staining. e Bar graphic representation of TUNEL staining results (GFP: $17.6 \pm 30.63 \%, n=3 ;$ CA: $14.4 \pm 3.31 \%$, $n=3$; DN: $39.08 \pm 8.46 \%, n=3$; One-way ANOVA, $F_{2,8}=6.50, P=0.0315$, Newman-Keuls multiple comparison test: $\left.{ }^{*} P<0.05\right)$

The 6-OHDA treatment significantly decreased the value of p-PAK1/PAK1 in the midbrains (Fig. 2c, d). Next, in order to exclude the effects of PAK1 in glial cells, we examined the level of p-PAK1 in response to 6-OHDA treatment in cultured mesencephalic DA neurons. Consistent with our previous data, the 6-OHDA treatment decreased the p-PAK1 level in TH-positive neurons, but it did not decrease the PAK1 level (Additional file 3: Figure S3). These results show that phosphorylation of PAK1 is decreased by oxidative stress.

\section{PAK1 activity could be recovered by PP2B inhibition}

We tried to identify an upstream protein phosphatase (PP) which has an effect on PAK1 by oxidative stress. In order to address, the SH-SY5Y cells were treated with 6-OHDA together with Cantharidic acid for inhibition of PP2A and PP1, Cypermethrin for inhibition of PP2B, or Okadaic acid for inhibition of PP2A. The Cypermethrin treatment blocked the down-regulation of PAK1 activity, suggesting that PP2B might be an upstream phosphatase of PAK1 in the signaling induced by oxidative stress (Fig. 3a). Cyclosporin A, a widely used immunosuppressant, is also a potent inhibitor of $\mathrm{PP} 2 \mathrm{~B}$, and it has been reported as a neuroprotective agent in experimental models of Parkinsonism [21]. Hence, in the subsequent experiment, we examined whether Cyclosporin A or Cypermethrin could rescue the viability of 6-OHDA treated cells. As expected, both Cyclosporin A and Cypermethrin could significantly rescue cell viability from oxidative stress (Fig. 3b).

\section{PAK1-DN expression decreases the level of $\mathrm{Bcl}-2$ protein} Previous studies $[10,11]$ indicate that activation of PAK1 by IL3 directly or indirectly increase the phosphorylation level of Bad, a pro-apoptotic Bcl-2 family protein, consequently reducing the interaction between $\mathrm{Bad}$ and $\mathrm{Bcl}-2$, and thereby increasing cell survival in FL5.12 lymphoid progenitor cells. In contrast, the autoinhibitory domain of PAK1 (amino acids 83-149) enhanced apoptotic cell death [11]. Additionally, the down-regulation of $\mathrm{Bcl}-2$ level was correlated with the activity of PAK1 (Fig. 2). Thus, in order to identify the molecular mechanisms implicated in apoptotic cell death caused by down-regulation of PAK1 activity, we examined the level of the members of anti-apoptotic and pro- 
a

$50 \mu \mathrm{M}$ 6-OHDA

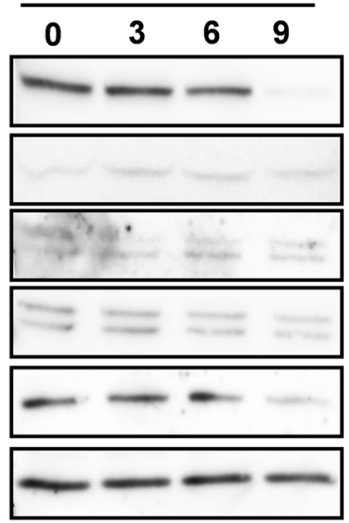

C

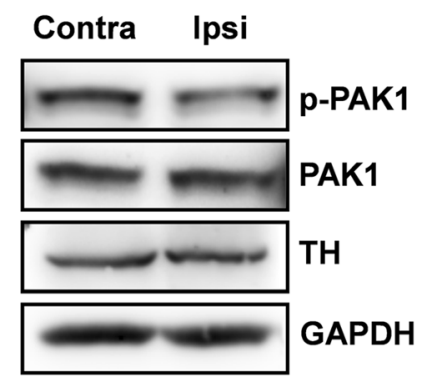

b
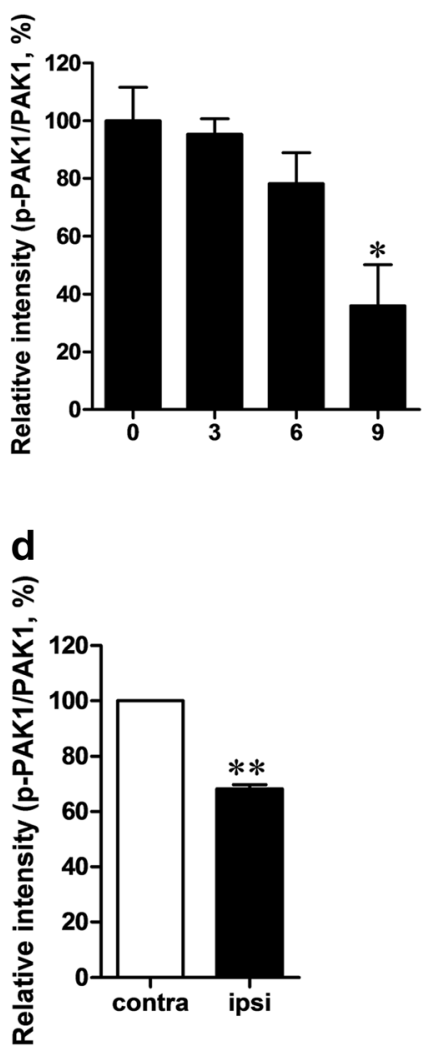

Fig. 2 Oxidative stress induced by 6-OHDA treatment reduces phosphorylated PAK1. a SH-SY5Y cells were treated with $50 \mu \mathrm{M}$ of 6-OHDA and harvested at 0, 3, 6, and $9 \mathrm{~h}$ after treatment. The lysates were used to measure phosphorylated PAK1 and total PAK1 levels by Western blot analysis. b Bar graphic representation of Western blot analysis [0 h: $100.0 \pm 11.61 \%, n=3 ; 3$ h: $95.4 \pm 5.35 \%, n=3 ; 6$ h: 78.2 $\pm 10.76, n=3 ; 9$ h: $36.0 \pm 14.19 \%, n=3$, One-way ANOVA, $F_{3,11}=7.070, P=0.0122$, Newman-Keuls multiple comparison test: $\left.{ }^{*} P<0.05\right]$. c A $4 \mu$ l dose of 6-OHDA (5 $\mu \mathrm{g} / \mu \mathrm{ll})$ was infused into the right striatum at rate of $0.5 \mu \mathrm{l} / \mathrm{min}$. After 7 days, the midbrain regions including the substantia nigra of the ipsilateral side and contralateral side were isolated and $30 \mu \mathrm{g}$ of each protein was used for Western blot analysis. $\mathbf{d}$ Bar graphic representation of Western blotting analysis (Contra: $100.0 \%, n=3$; Ipsi: $68.2 \pm 1.56 \%, n=3$, Paired t-tests, ${ }^{* *} P<0.001$ )
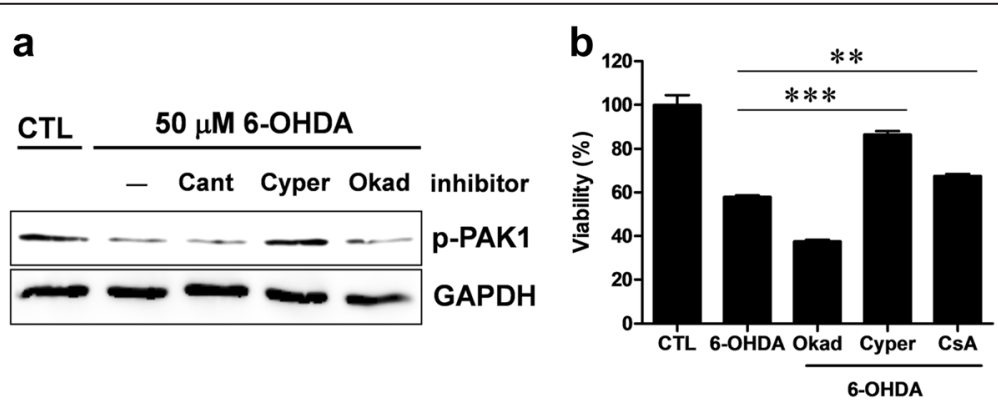

Fig. 3 PP2B inhibitor reverses the down-regulation of PAK1 activity induced by oxidative stress. a SH-SY5Y cells were treated with $50 \mu \mathrm{M}$ 6-OHDA along with $200 \mathrm{nM}$ Cantharidic acid, $0.2 \mathrm{nM}$ Cypermethrin, or $0.5 \mathrm{nM}$ Okadaic acid for $9 \mathrm{~h}$. The cell lysates were harvested and subjected to Western blotting. b SH-SY5Y cells were treated with $50 \mu \mathrm{M}$ 6-OHDA along with $0.5 \mathrm{nM}$ Okadaic acid (Okad), 0.2 nM Cypermethrin (Cyper), or $10 \mu \mathrm{M}$ Cyclosporin A (CSA) for $9 \mathrm{~h}$ and subjected to cell viability assay. Both Cypermethrin and Cyclosporin A treatment significantly blocked cell death, but Okadaic acid treatment did not block cell death (CTL: $100.0 \pm 4.48 \%, n=6 ; 6-\mathrm{OHDA}: 58.0 \pm 0.74 \%, n=6 ;$ Okad: $37.6 \pm 0.69 \%, n=6$; Cyper: $86.6 \pm 1.55 \%, n=6 ;$ CsA: $67.5 \pm 0.90 \%, n=6$, One-way ANOVA, $F_{4,29}=122.3$, ${ }^{* * * *} P<0.0001$, Newman-Keuls multiple comparison test: $\left.{ }^{* *} P<0.01,{ }^{* * *} P<0.001\right)$ 
apoptotic Bcl-2 family proteins induced by PAK1-DN expression. As shown in Fig. 4a, Bcl-2 and $\mathrm{Bcl}-\mathrm{x}_{\mathrm{L}}$, members of anti-apoptotic Bcl-2 family proteins, were downregulated by the PAK1-DN expression. Also, the downregulation of proteins was recapitulated in the transient expression of PAK1-DN plasmid vector in human embryonic kidney (HEK) 293T cells (Additional file 4: Figure S4). Consequently, to identify the molecular mechanisms involved in the down-regulation, we examined the mRNA levels of Bcl-2 and Bcl- $\mathrm{x}_{\mathrm{L}}$ by RT-PCR analysis. Interestingly, the decrease in the protein level by PAK1-DN expression was not correlated with the level of each mRNA, suggesting a regulatory mechanism in the post-translational stage (Additional file 5: Figure S5).

In order to further clarify whether the decrease of Bcl2 or $\mathrm{Bcl}-\mathrm{x}_{\mathrm{L}}$ is a specific event regulated by PAK1-DN, we examined the dose-dependency of $\mathrm{Bcl}-2$ decrease induced by PAK1-DN. The HEK 293T cells were transfected with 1, 1.5, 2, or $3 \mu \mathrm{g}$ of PAK1-DN plasmids, and subsequently the protein levels of $\mathrm{Bcl}-2$ or $\mathrm{Bcl}-\mathrm{x}_{\mathrm{L}}$ were examined. As shown in Fig. 4b, c, the level of Bcl-2 was inversely correlated with the level of PAK1-DN. The decrease in Bcl- $\mathrm{x}_{\mathrm{L}}$ was only evident in cells transfected with $3 \mu \mathrm{g}$ of PAK1-DN plasmids, but it did not show any dose-dependency. In the subsequent experiments, we examined the levels of Bcl-2 and Bcl- $\mathrm{x}_{\mathrm{L}}$ induced by the expression of PAK1-WT, PAK1-CA, or other inactive-form mutants $\left(\mathrm{PAK} 1^{\mathrm{H} 83,86 \mathrm{~L}}, \mathrm{PAK} 1^{\mathrm{K} 299 \mathrm{R}}\right.$, PAK1 67-150 amino acids). No alteration in the Bcl-2 level was detected, except PAK1 ${ }^{\text {K299R }}$ or PAK1 $67-150$ aa expression. The levels of $\mathrm{Bcl}-\mathrm{x}_{\mathrm{L}}$ induced by transient expression of PAK1 mutants were not altered in all results, being different from those induced by stable expression of PAK1-DN (Additional file 6: Figure S6).

Previous studies have reported that the cellular level of $\mathrm{Bcl}-2$ is modulated by the ubiquitin/proteasomedependent pathway and this degradation is dependent on the phosphorylation status of $\mathrm{Bcl}-2$, which is
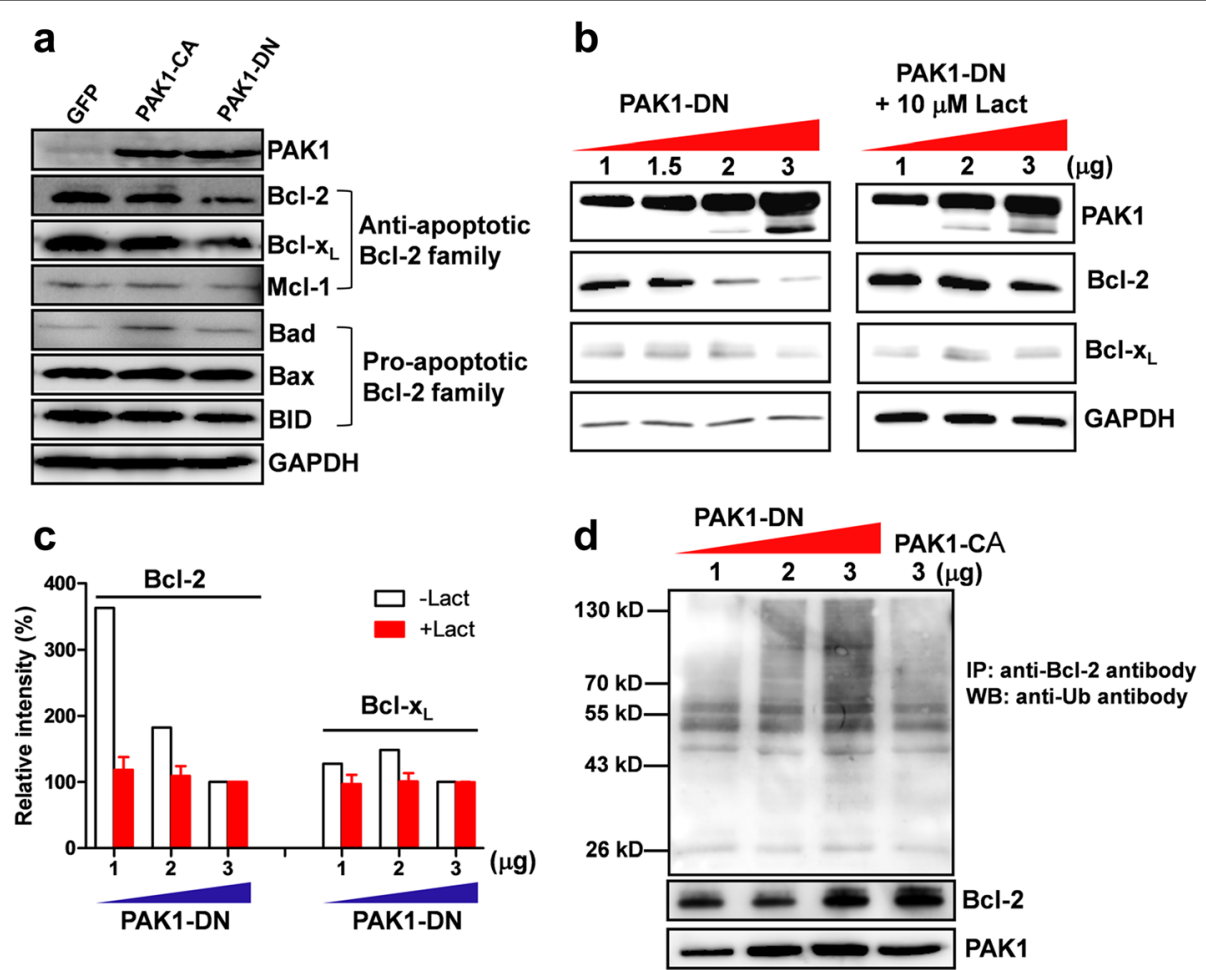

Fig. 4 PAK1-DN expression reduces the BCl-2 level. a PAK1-DN expression reduces level of anti-apoptotic Bcl-2 family proteins. Lysates of SH-SY5Y cells expressing GFP, PAK1-CA, or PAK1-DN were subjected to Western Blot analysis using antibodies against anti-apoptotic or pro-apoptotic Bcl-2 family proteins. $\mathbf{b}$ Reduction in $\mathrm{BCl}-2$ induced by PAK1-DN expression is mediated by ubiquitin-dependent protein degradation. HEK cells were transfected with $1,1.5,2$, or $3 \mu \mathrm{g}$ of PAK1-DN vector and incubated for $36 \mathrm{~h}$ and treated with $10 \mu \mathrm{M}$ lactacystin or without for $12 \mathrm{~h}$. The cell lysates were subjected to Western blot analyses using the indicated antibodies. c Quantification of Western blot analysis. To obtain relative values of BCl-2 or BCl-xL level, band intensities from 1 and $2 \mu \mathrm{g}$ expression of PAK1-DN was normalized by that from $3 \mu \mathrm{g}$ expression of PAK1-DN in each blot. Reduction in Bcl-2 induced by dose-dependent expression of PAK1-DN reversed by lactacystin treatment [-Lact: $362.68 \%(1 \mu \mathrm{g}) \rightarrow 182.6 \%(2 \mu \mathrm{g}) \rightarrow 100.0 \%(3 \mu \mathrm{g})$, +Lact: 118.5 $\pm 19.26 \%, n=3(1 \mu \mathrm{g}) \rightarrow 109.05 \pm 15.10 \%, n=3(2 \mu \mathrm{g}) \rightarrow 100.0 \%, n=3(3 \mu \mathrm{g})]$. Bcl-XL level was not altered [-Lact: $127.7 \%(1 \mu \mathrm{g}) \rightarrow 148.4 \%(2 \mu \mathrm{g}:) \rightarrow$ $100.0 \%(3 \mu \mathrm{g})$, +Lact: $97.0 \pm 13.89 \%, n=3(1 \mu \mathrm{g}) \rightarrow 100.94 \pm 12.59 \%, n=3(2 \mu \mathrm{g}) \rightarrow 100.0 \%, n=3(3 \mu \mathrm{g})]$. d PAK1-DN expression increased the ubiquitination of $\mathrm{BCl}-2$ protein, but PAK1-CA expression did not increase the ubiquitination of $\mathrm{BCl}-2$ protein 
modulated by mitogen-activated protein (MAP) kinase $[22,23]$. Hence, we examined whether the downregulation of $\mathrm{Bcl}-2$ by PAK1-DN is dependent on the ubiquitin/proteasome-dependent pathway. As shown in Fig. 4b, c, the down-regulation of Bcl-2 level by PAK1$\mathrm{DN}$ was completely blocked by $10 \mu \mathrm{M}$ lactacystin, an inhibitor of the ubiquitin/proteasome-dependent pathway. In addition, treatment with MG-132, another specific inhibitor to the ubiquitin/proteasome-dependent pathway, showed the same results (data not shown). Consequently, in the subsequent experiment, we examined the ubiquitination of $\mathrm{Bcl}-2$ induced by PAK1-DN expression. Indeed, PAK1-DN expression predominantly increased the ubiquitination level of Bcl-2 protein (Fig. 4d). These results suggest that PAK1 activity could modulate the $\mathrm{Bcl}-2$ level via the ubiquitin/proteasome-dependent mechanism.

\section{Bcl-2 level could be modulated by both PAK1-MAPK} signaling and PAK1 directly

As previously described, $\mathrm{Bcl}-2$ protein is down-regulated by the ubiquitin/proteasome-dependent mechanism and this degradation is dependent on the phosphoryation status of Bcl-2, which is modulated by the mitogenactivated protein kinase (MAPK) pathway [22, 23]. Hence, we examined whether the down-regulation of Bcl-2 by PAK1-DN expression could be rescued by extracellular signal-regulated kinase (ERK) expression. As a result, the down-regulation of Bcl-2 by PAK1-DN expression was recovered by ERK2 expression (Fig. 5a). In order to further clarify this result, serine 87 on Bcl-2, which is reported to be a major site for phosphorylation by MAP kinase, was changed to aspartic acid, mimicking phosphorylation $\left(\mathrm{Bcl}-2^{\mathrm{S} 87 \mathrm{D}}, \mathrm{S} 87 \mathrm{D}\right)$ or an alanine residue $\left(\mathrm{Bcl}-2^{\mathrm{S} 87 \mathrm{~A}}, \mathrm{~S} 87 \mathrm{~A}\right)$. As expected, the level of S87D was not altered by PAK-DN expression. These results suggest that the Bcl-2 level could be modulated by the PAK1MAPK pathway.

We questioned whether the level of $\mathrm{Bcl}-2$ might be directly regulated by PAK1. A putative site for phosphorylation by PAK1 on the amino acid sequences of human Bcl-2 was examined using GPS 2.1.2 (Group-based Prediction system), a kinase-specific prediction program [24]. Serine 70 was isolated as a putative site for phosphorylation by STE20/PAK1. We constructed mutants in which serine 70 was changed to glutamic acid (Bcl$\left.2^{\mathrm{S} 70 \mathrm{E}}, \mathrm{S} 70 \mathrm{E}\right)$ or alanine $\left(\mathrm{Bcl}-2^{\mathrm{S} 70 \mathrm{~A}}, \mathrm{~S} 70 \mathrm{~A}\right)$, and we examined the level of each Bcl-2 mutant induced by PAK1$\mathrm{DN}$ expression. Interestingly, S70E was resistant to the degradation mediated by PAK1-DN expression (Fig. 5b). In order to examine the association of PAK1 with Bcl-2, we performed coimmunoprecipiation (co-IP) assay. PAK1-CA was associated with Bcl-2 immunecomplexes and this association was much stronger than that of PAK1-DN with Bcl-2 immunecomplexes (Fig. 5c). Taken together, these data suggest that Bcl-2 level could be modulated by PAK1-MAPK signaling and/or PAK1 directly.
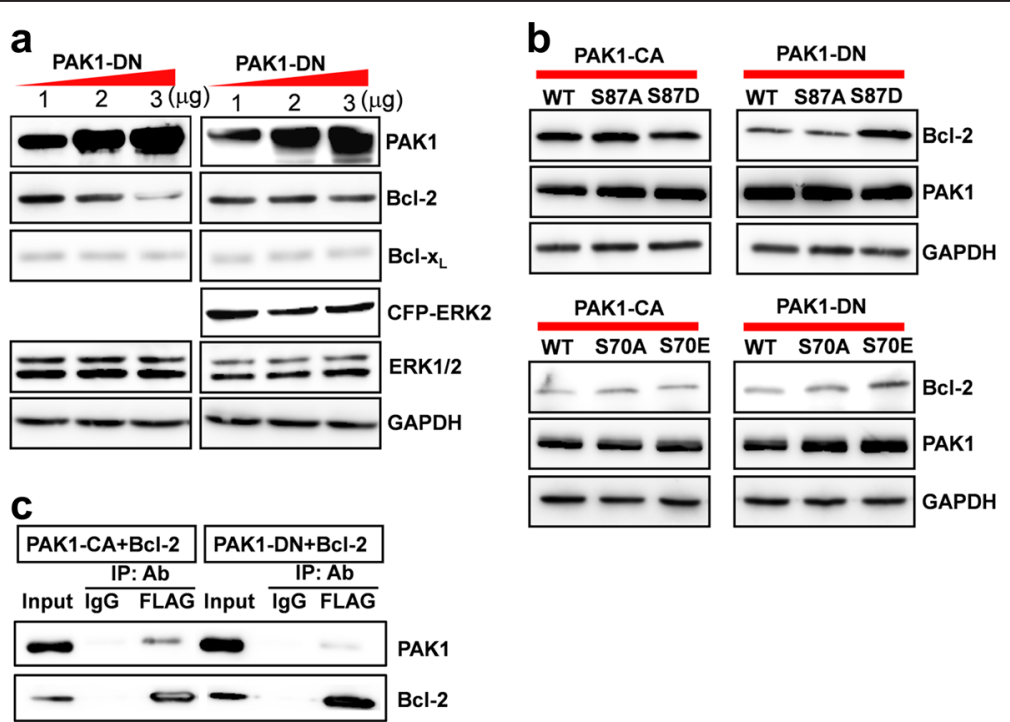

Fig. 5 Reduction in the Bcl-2 level induced by PAK1-DN is mediated by PAK1-ERK or PAK1 directly. a HEK 293T cells were transfected with 1, 2, or $3 \mu \mathrm{g}$ of PAK1-DN vectors and with $1 \mu \mathrm{g}$ of CFP-ERK2 or without CFP-ERK2. Dose-dependent reduction in the BCl-2 level induced by PAK1-DN was blocked by ERK2 expression. b Bcl-2 ${ }^{\mathrm{SBDD}}$ (serine $87 \rightarrow$ aspartic acid), a phosphomimetic form by ERK was resistant to PAK1-DN expression. Bcl-2 ${ }^{\mathrm{S} 87}$ (serine $87 \rightarrow$ alanine) did not show resistance to PAK1-DN expression. BCl-2 ${ }^{\text {S70E }}$ (serine $70 \rightarrow$ glutamic acid), a putative phosphomimetic form by PAK1 was also resistant to PAK1-DN expression. All BCl-2 mutants were not altered by PAK1-CA expression. c HEK 293T cells were transfected with FLAG-tagged BCl-2 and Myc-tagged PAK1-CA or PAK1-DN vectors. The cell lysates were immunoprecipitated with anti-FLAG antibody and the resulting immunoprecipitates were subjected to Western blot analysis using anti-Myc antibody 
PAK1-CA recovers behavioral and cellular defects in hemiparkinsonian rat model

The catecholamine neurotoxin, 6-hydroxydopamine (6OHDA) has been widely used to PD model $[25,26]$. We examined the effect of PAK1-CA expression on the DA neuron survival and animal behavior in a 6-OHDAinduced hemiparkinsonian rat model. In order to induce progressive death of nigral neurons, 6-OHDA was injected into the striatum, and subsequently, lentiPAK1-CA or lenti-GFP virus was injected into the ipsilateral substantia nigra pars compacta $(\mathrm{SNpc})[27,28]$. During 3 weeks, behavioral assay was performed to examine forelimb-use asymmetry at every week (Fig. 6a) $[25,29,30]$. Finally, tyrosine hydroxylase (TH)-positive neurons in the ipsilateral SNpc were measured by comparing with $\mathrm{TH}$-positive neurons in the contralateral SNpc. As shown in Fig. 6b, c, PAK-CA expression in the substantia nigra significantly blocked the loss of $\mathrm{TH}$ positive neurons induced by 6-OHDA treatment. Consistent with cellular protection, the PAK1-CA expression significantly recovered behavioral defects from 2 weeks after the infusion and infection, compared to those in the GFP-expressing control group. Additionally, the recovery from loss of TH-positive neurons and behavioral

\section{a Cylinder test Virus injection/6-OHDA \\ Cylinder test/

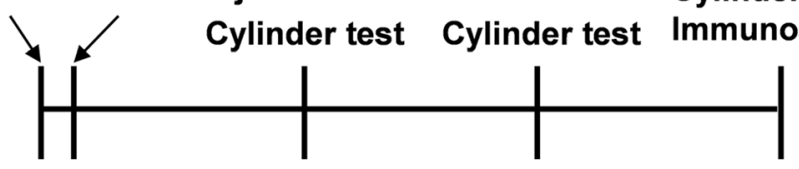 \\ pre 1day \\ 1 week \\ 2 week \\ 3 week}

b

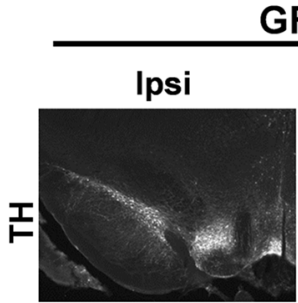

GFP

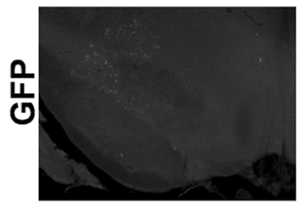

C

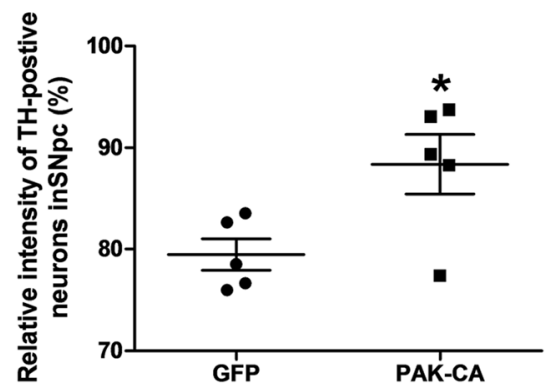

\section{Contra}
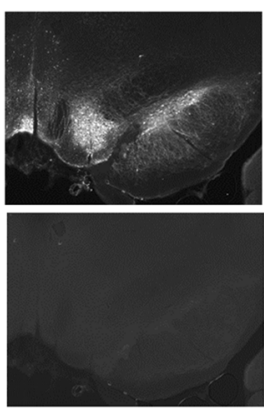

PAK1-CA

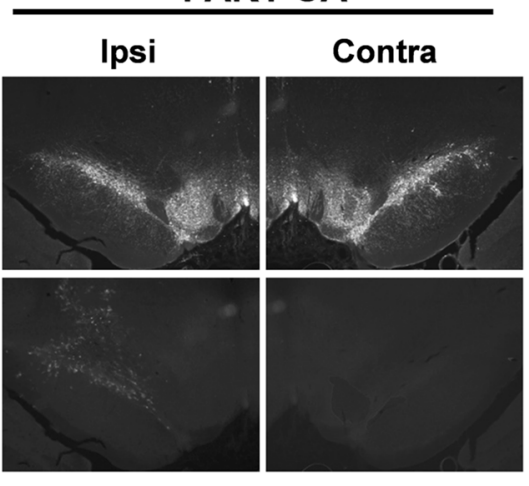

d

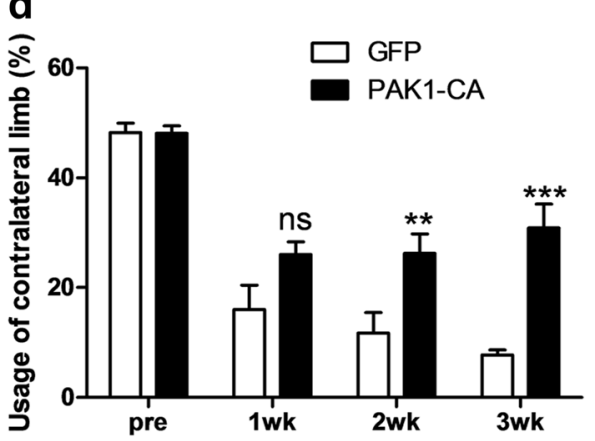

Fig. 6 PAK1-CA expression recovers behavioral defect and loss of mesencephalic dopamine neurons. a Experimental scheme and procedure. $\mathbf{b}$ Lentiviruses encoding GFP or PAK1-CA were infused into the right SNpc at rate of $0.5 \mu \mathrm{l} / \mathrm{min}$ at the following coordinates: anteroposterior, -5.3 $\mathrm{mm}$ from the bregma; mediolateral, $2.3 \mathrm{~mm}$; dorsoventral, $-7.3 \mathrm{~mm}$ below surface of the dura. After 3 weeks, the midbrain tissue sections were immunostained with anti-Tyrosine Hyroxylase antibody and visualized by immunostaining using Cy3-conjugated goat anti-rabbit IgG antibody. c The loss of DA neurons in the SNpc induced by 6-OHDA treatment was blocked by PAK1-CA expression, but not by GFP expression (GFP: 79.5 \pm $1.55 \%, n=5$, compared to the ipsilateral side; PAK1-CA: $88.4 \pm 2.94 \%, n=5$, compare to ipsilateral side, Student's $t$-tests, $\left.{ }^{*} P<0.05\right)$. d PAK1-CA expression significantly improved usage of the contralateral limb in a hemiparkinsonian animal model (GFP: PAK1-CA, pretest, 48.2 $\pm 1.69, n=5$ : $48.08 \pm 1.37, n=8 ; 1$ week, $16.0 \pm 4.46, n=5: 26.00 \pm 2.30, n=8 ; 2$ weeks, $11.7 \pm 3.73, n=5: 26.21 \pm 3.58, n=8 ; 3$ weeks, $7.8 \pm 0.93, n=4: 30.88 \pm$ 4.32, $n=6$; Two-way ANOVA, $F_{3,41}=39.40,{ }^{* * *} P<0.0001$, Bonferroni multiple comparison tests, ns: not significant, ${ }^{* *} P<0.01,{ }^{* * *} P<0.001$ ) 
defects by the PAK1-CA expression was recapitulated in 1-Methyl-4-phenyl-1,2,3,6-tetrahydropyridine hydrochloride (MPTP)-induced hemiparkinsonian rat model (Additional file 7: Figure S7). These data strongly suggest that the activity of PAK1 could be related with the survival of TH-positive neurons and behaviors.

\section{Discussion}

Since a very long time, there have been many discussions on the inverse comorbidity between some cancers and neurodegenerative diseases [17]. A genetic determinant can decide the fate of cells, depending on the situations or the characteristic of cells [18]. Previous studies have described that overactivation or overexpression of PAK1 is strongly correlated with cancers $[4,5]$. In our study, down-regulation of PAK1 activity, and not amount, was correlated with cell death and that occurs at the initial stage of cell death induced by oxidative stress, such as 6OHDA treatment (Fig. 1, 2). These results suggest that PAK1 might function as a molecular determinant that may decide the direction for development of neurodegenerative diseases, such as Parkinson's disease (Fig. 7).

It has been widely accepted that apoptosis (type I cell death) is the major cause of neuronal loss in PD [31]. Some studies, using postmortem brain sections of PD patients, have reported that loss of the nigral neurons is due to apoptosis induced by an increase in Bax (a proapoptotic member of the Bcl-2 family)-dependent mitochondrial membrane permeability [31-33]. If cell fate is determined by the ratio of pro-apoptotic to antiapoptotic proteins, a reduction in Bcl-2 could increase Bax-triggered apoptosis. Of course, some part of this apoptotic cell death might originate from dephosphorylation of Bad induced by inactivation of PAK signaling
$[10,11]$. However, if we consider that the expression of Bax in the melanized nigral neurons is more related with PD brains [32, 33], Bax-triggered apoptosis induced by the reduction in Bcl-2 could be a major pathway. Even in our conclusion, the possibility that two pathways act synergistically or simultaneously, cannot be excluded. Thus, in order to clarify this, more studies are needed.

Unwanted proteins should be cleared by cellular clearance systems. The failure of clearance system could increase the number of misfolded and aggregated proteins. Thus, the ubiquitin-proteasome system is closely linked with the development of PD. Indeed, mutations of genes involved in the ubiquitin-proteasome system are found in several types of familial PD and proteasomal enzymatic activity is reduced in sporadic PD [34]. In our study (Fig. 2, 3) and previous reports [22, 23], oxidative stress regulated PAK1 activity. Subsequently, PAK1 could regulate the level of $\mathrm{Bcl}-2$ protein through the ubiquitinproteasome system by modulating its phosphorylation status through the extracellular signal-regulated kinase (ERK) pathway [22, 23]. However, these mechanisms only work when ubiquitin-proteasome system is intact or partially working. Protein aggregates, known as Lewy bodies, in nigral neurons have toxic effects. Production of protein aggregates might be due to an imbalance between the amount of unwanted proteins and the capacity to remove them. Indeed, the reduction of removal capacity is correlated with aging $[35,36]$.

Extracellular signals that lead to the activation or inactivation of PAK1 have not been clearly elucidated. In particular, inactivation mechanisms including dephosphorylation mechanisms still remain to be elucidated. Although PP2A [37, 38], POPX1/2 [39] and PP2C [40] have been reported as PAK1 regulators in different

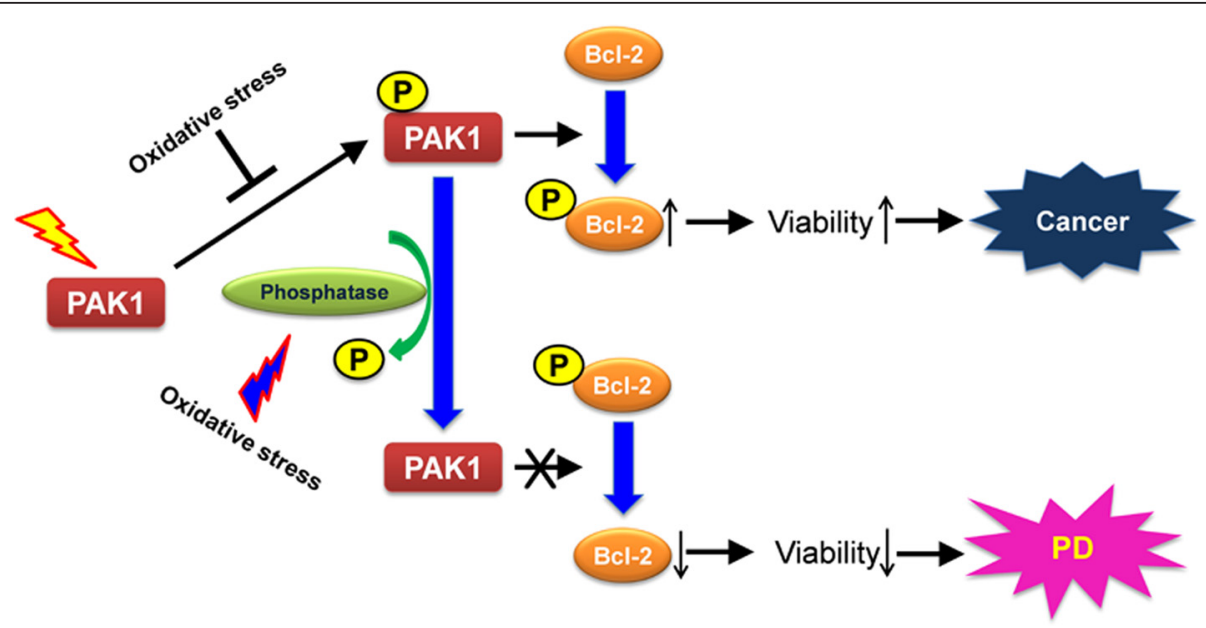

Fig. 7 Model of PAK1 roles in the pathogenesis of diseases. An oxidative stress might induce activation of a phosphatase for PAK1 or inhibit phosphorylation of PAK1 via other mechanisms. Consequently, the down-regulation of PAK1 activity decreases the phosphorylation of Bcl-2 and the dephosphorylated $\mathrm{BCl}-2$ proteins are to be more susceptible to an ubiquitin/proteasome-dependent degradation. Reduction of $\mathrm{Bcl}-2$ level induces loss of cells, such as mesencephalic dopamine neurons, thereby inducing Parkinson's disease (PD) 
cellular contexts, there has been no report on the phosphatase for PAK1 in response to oxidative stress. Our data suggest calcineurin, $\mathrm{PP} 2 \mathrm{~B}$, as a phosphatase for PAK1 in the signaling involved in oxidative stress (Fig. 3a). Indeed, the inhibitors of PP2B decreased the death rate of neuroblastoma cells induced by 6-OHDA treatment (Fig. 3b), suggesting a new target for PD therapy. For treatment of PD, levodopa (L-dopa), a dopamine precursor has been widely used. However, long-term treatment causes some side effects such as psychiatric symptoms, wearing-off phenomenon, or on/ off phenomenon. The focus of new therapy has been on the development of agents that suppress or delay neuronal death [21]. Cyclosporin A, an immunosuppressant, has been used to suppress the immune response after transplantation. Interestingly, treatment of Cyclosporin A protects cortical neurons from traumatic brain injury $[41,42]$ and attenuates the decrease of tyrosine hydroxylase in the nigrostriatal DA neurons and DA neurons itself in a 6-OHDA animal model of PD [21]. Our data also showed that treatment with Cyclosporin A increased the viability of neuroblastoma cells treated with the neurotoxin, 6-OHDA (Fig. 3). Thus we suggest a novel molecular mechanism for neuroprotective effects of Cyclosporin A. Inactivation of PAK1 induced by oxidative stress might be blocked by the inhibition of $\mathrm{PP} 2 \mathrm{~B}$ by Cyclosporin A, thereby increasing cell viability (Fig. 7). However, more studies are required for the clinical application of Cyclosporin A in PD patients.

\section{Methods}

\section{Experimental animal}

Adult female $(\sim 230 \mathrm{~g})$ and postnatal 1-day-SpragueDawley rats were purchased from SAMTAKO (Osan, Korea) for the animal model of Parkinson's disease and the culture of dopamine neurons, respectively. All experiments were performed in accordance with the approved animal protocols and the guidelines of the Institutional Animal Care and Use Committee of Chungbuk National University (CBNUA-432-12-02).

\section{Cell culture}

Human embryonic kidney (HEK) 293T cells were cultured in Dulbecco's modified Eagle's medium (DMEM, GIBCO', Grand Island, NY, USA) supplemented with 7-10\% fetal bovine serum $(\mathrm{GIBCO})$ and supplied with $5 \% \mathrm{CO}_{2}, 37^{\circ} \mathrm{C}$. Human neuroblastoma cells (SH-SY5Y) were grown in Eagle's Minimum Essential Medium and F12 Medium supplemented with $10 \%$ fetal bovine serum (GIBCO ). To obtain culture of mesencephalic dopamine neurons, astrocytes were placed on collagen/poly-L-lysine coated coverglass and incubated for 7 days. Dopamine neurons isolated from the substantia nigra (SN) and ventral tegmental area (VTA) of post-natal 1-day-old rats were placed on the astrocyte monolayer and incubated for 16 days before use [43].

\section{DNA construction and lentivirus}

For expression of PAK1 and its mutants, PAK1 wild type (WT), kinase-active PAK $1^{\mathrm{T} 423 \mathrm{E}}$ (PAK1-CA) and dominantnegative PAK1 ${ }^{\mathrm{H} 83,86 \mathrm{~L}, \mathrm{~K} 299 \mathrm{R}}$ (PAK1-DN) [44] were inserted into the pCMV-myc vector (Clontech, Palo Alto, CA, USA) for cell line expressions, and into the pHJEF1a(sin) vector for lentiviral expression. For expression of ERK2, ERK2 was inserted into the pCFP-C1 vector (Clontech), resulting in PCFP-ERK2. The preparations of lentivirus and Sindbis virus were performed according to the previously described methods [45]. Human Bcl-2 mutants (S70E, S70A, S87D, and S87A) were made by recombinant PCR methods using the following primer sets: Bcl-2-S70E-S: $5^{\prime}$ aggaccgagccgctgcagacccegct-3', Bcl-2-S70E-A: 5' -tgcagcg gctcggtcctggcgaccggg-3', Bcl-2-S70A-S: 5' -aggaccgcgccgct gcagaccceggct-3;, Bcl-2-S70A-A: 5' -tgcagcggcgcggtcctggcg accggg-3', Bcl-2-S87D-S: 5' -gcgctcgacccggtgccacctgtggtcc a-3, Bcl-2-S87D-A, 5' -ggcaccgggtcgagcgcaggcccgcggc-3', Bcl-2-S87A-S: 5 '-gcgctcgccceggtgccacctgtggtcca-3', Bcl-2S87A-A: ggcaccggggcgagcgcaggcccegcggc-3' .

\section{Stable cell lines}

To obtain pure cell cultures expressing GFP, PAK1 wild type (WT), constitutively active PAK1 ${ }^{\text {T423E }}$ (PAK1-CA) mutant, or dominant-negative PAK1 ${ }^{\mathrm{H} 83,86 \mathrm{~L}, \mathrm{~K} 299 \mathrm{R}}$ (PAK1$\mathrm{DN}$ ) mutant, after lentiviral infection of encoding GFP only or each PAK1 mutant and bicistronically linked GFP, SH-SY5Y cells were sorted by a fluorescenceactivated cell sorter (FACSCalibur, BD Biosciences, Franklin Lakes, NJ, USA) using fluorescence of GFP, and stored.

\section{Cell viability assay and TUNEL staining}

For the viability assay, SH-SY5Y cells expressing GFP, PAK1-WT, PAK1-CA or PAK1-DN, were plated at $1 \mathrm{X} 10^{5}$ cells per well and incubated for $72 \mathrm{~h}$. For assessing viability following oxidative stress, cells were plated and incubated for $24 \mathrm{~h}$ and additionally incubated with $700 \mu \mathrm{M}$ hydrogen peroxide (Sigma-Aldrich, St Louis, MO, USA), $100 \mu \mathrm{M}$ 6-hydroxydopamine (Sigma-Aldrich), or without both for $12 \mathrm{~h}$. For the viability assay after phosphatase inhibitor treatment, SH-SY5Y cells $\left(1 \mathrm{X} 10^{5}\right.$ cells) were pretreated with $0.2 \mathrm{nM}$ Cypermethrin (Santa Cruz, Santa Cruz, CA, USA), 0.5 nM Okadaic acid (Sigma-Aldrich), or $10 \mu \mathrm{M}$ Cyclosporin A (Tocris, Bristol Avonmouth, UK) for $30 \mathrm{~min}$ and subsequently treated along with $50 \mu \mathrm{M}$ 6-OHDA for $8 \mathrm{~h} 30 \mathrm{~min}$. The number of viable cells was determined by colorimetric assay using WST-8 (Dojindo Laboratories, Kumamoto, Japan). To measure apoptotic cell death, at $72 \mathrm{~h}$ after cell plating, cultures were subjected to TUNEL staining 
using In Situ Cell Death Detection kit (Roche, Basel, Switzerland). The apoptosis rates were determined by the number of TUNEL-positive cells in that of GFPpositive cells on three culture dishes for each condition.

\section{Western blotting}

SH-SY5Y cells expressing GFP, PAK1-CA, or PAK1-DN were plated and incubated for $72 \mathrm{~h}$. The cultured HEK 293T cells were transfected with the indicated plasmids and GFP vector, thus making up the total amount of plasmids used in transfection to $3 \mu \mathrm{g}$, and were incubated $48 \mathrm{~h}$ to induce expression. For lactacystin (Tocris) treatment, after $36 \mathrm{~h}$ of incubation, transfected cells were treated with $10 \mu \mathrm{M}$ lactacystin for $12 \mathrm{~h}$. For Western blot analysis, the lysates of cells were prepared by adding the lysis buffer $\left(150 \mathrm{mM} \mathrm{NaCl}, 1 \%\right.$ IGEPAL $^{\circ}$ CA-630, $50 \mathrm{mM}$ Tris.Cl $[\mathrm{pH} 8.0]$ ), separated on the SDS-PAGE and transferred to PVDF membrane (Millipore, Billerica, MA, USA). The blots were incubated with the indciated antibody. For control, the blot was washed with stripping buffer (Thermo Scientific, Rockford, IL, USA) and re-probed. Antibodies used in Western blot analyses were as follows: anti-FLAG antibody (M2, F1804, Sigma-Aldrich), anti-c-Myc-antibody (9E10, M4493, Sigma-Aldrich), anti-Bcl-2 antibody (50E3, \#2870, Cell Signaling, Danvers, MA, USA), anti-Bcl- $x_{\mathrm{L}}$ antibody (54H6, \#2764, Cell Signaling), anti-Mcl-1 antibody (\#4572, Cell Signaling), anti-Bad antibody (\#9292, Cell Signaling), anti-Bax antibody (\#2772, Cell Signaling), anti-BID antibody (\#2002, Cell Signaling), antiPAK1 polyclonal antibody (N-20, sc-882, SANTA CRUZ Biotechnology), anti-phosphorylated PAK1 antibody (Thr 423, sc-21903-R, SANTA CRUZ Biotechnology), anti-ERK1/2 antibody (\#9102, Cell Signaling), phosphorylated ERK2 (Thr202/Tyr204, \# 9101, Cell Signaling), anti-tyrosine hydroxylase antibody (AB152, Millipore, Billerica, MA, USA).

\section{Ubiqutination assay}

HEK cells were transfected with the indicated amount of PAK1-DN or PAK1-CA plasmids, incubated for $36 \mathrm{~h}$, treated with $10 \mu \mathrm{M}$ lactacystin (Tocris) for $12 \mathrm{~h}$ and subjected to immunoprecipitation with anti-Bcl-2 antibody (Cell Signaling). Immunoprecipitates were subjected to Western blot analysis using anti-monoclonal mono- and polyubiquitinylated conjugates antibody (FK2, BMLPW8810, Enzo Life Sciences, Farmingdale, NY, USA).

\section{Immunostaining}

Cultured neurons were treated with $100 \mu \mathrm{M}$ of 6-OHDA for $9 \mathrm{~h}$, fixed with $4 \%$ paraformaldehyde solution. Immunocytochemistry was conducted as described in a previous study [46]. For immunohistochemistry, anesthetized animals were dissected and fixed by vascular perfusion with $4 \%$ paraformaldehyde solution through the heart. Total brain was isolated and additionally incubated with $4 \%$ paraformaldehyde solution for $24 \mathrm{~h}$. Then brain tissues were incubated with $20 \%$ sucrose solution for $36-48 \mathrm{~h}$, mounted in OCT embedding compound, frozen at $-80{ }^{\circ} \mathrm{C}$, and coronally cut into $30 \mu \mathrm{m}$ thick tissue sections by a cryostat (Leica 1650, Leica, Wetzlar, Germany). Neuronal cultures and tissue sections were permeabilized with PBST $(0.1 \%$ Triton X100, $0.2 \%$ BSA, 1X PBS, pH7.4), and blocked with a preblocking agent ( $2 \%$ BSA, $0.08 \%$ Triton X-100, 1X PBS, $\mathrm{pH7}$.4). The cultures were treated with PAK1 or p-PAK1 antibody and visualized by secondary staining with Cy3conjugated goat anti-rabbit IgG antibody (111-165-144, Jackson ImmunoResearch Laboratories, West Grove, PA). Tissue sections were treated with anti-Tyrosine Hydroxylase antibody (Millipore) and subsequently immunostained with Cy3-conjugated goat anti-rabbit IgG antibody. Immunostained cells and tissue sections were acquired by an up-right fluorescence microscope (BX51, Olympus, Tokyo, Japan) equipped with a CCD camera (DP30BW, Olympus) and the images were analyzed by NIH image analysis program (ImageJ ver $1.47 \mathrm{v}$, Bethesda, MA, USA).

\section{Phosphatase inhibitor assay}

SH-SY5Y cells were pretreated with $200 \mathrm{nM}$ Cantharidic acid (Santa Cruz Biotechnology), $0.2 \mathrm{nM}$ Cypermethrin (Santa Cruz Biotechnology), or $0.5 \mathrm{nM}$ Okadaic acid (Sigma-Aldrich) for $30 \mathrm{~min}$ and treated along with 50 $\mu \mathrm{M}$ 6-OHDA for $8 \mathrm{~h} 30 \mathrm{~min}$. The cell lysates were subjected to Western blot analysis.

\section{Stereotaxic surgical procedure}

Adult female Sprague-Dawley rats $(\sim 230 \mathrm{~g})$ were anesthetized by a subcutaneous injection of a Zoletil/Rompun cocktail solution $(5 \mathrm{mg} / \mathrm{kg}$ Zoletil 50, Virbac Laboratories, Carros, France; $0.5 \mathrm{ml} / \mathrm{kg}$ Rompun, Bayer, Berlin, Germany). Animals were placed into a stereotaxic frame (ASI Instruments, Warren, MI, USA). Burr holes were drilled to allow a single unilateral injection of 6OHDA or a double injection of 6-OHDA or saline and lentivirus. A $4 \mu \mathrm{l}$ dose of 6 -OHDA $(5 \mu \mathrm{g} / \mu \mathrm{l})$ was infused into the right striatum at a rate of $0.5 \mu \mathrm{l} / \mathrm{min}$ at the following coordinates: anteroposterior, $1.0 \mathrm{~mm}$ from the bregma; mediolateral, $-3.0 \mathrm{~mm}$; dorsoventral, $-5.0 \mathrm{~mm}$ below surface of the dura [27]. A $2 \mu \mathrm{l}$ dose of lentivirus encoding GFP or PAK1-CA (1-2 X10 $7 \mathrm{TU} / \mathrm{ml})$ was infused into the right $\mathrm{SNpc}$ at a rate of $0.5 \mu \mathrm{l} / \mathrm{min}$ at the following coordinates: anteroposterior, $-5.3 \mathrm{~mm}$ from the bregma; mediolateral, $-2.3 \mathrm{~mm}$; dorsoventral, $-7.3 \mathrm{~mm}$ below surface of the dura [27]. 


\section{Behavioral test (cylinder test)}

A unilateral lesion of the nigrostriatal pathway was measured by examining the asymmetry in forelimb usage $[29,30]$. Experimental animals were placed in a transparent cylinder, $30 \mathrm{~cm}$ high and $20 \mathrm{~cm}$ in diameter, for 5 min. The contact with the wall by the impaired, unimpaired or both forelimbs was scored and presented as percentage. Animals which showed usage of the left or right forelimb in a pretest up to more than $70 \%$ were excluded in subsequent experiments.

\section{Statistical analysis}

All data are presented as mean \pm SEM. Statistical significance between the two groups was measured by Student's $t$-tests and that among more than three groups by ANOVA analysis with an appropriate post-hoc test. Statistical difference in cell viability induced by PAK1 and its mutants was analyzed by one-way ANOVA and Newman-Keuls multiple comparison test. Animal behavior was analyzed by two-way ANOVA and Bonferroni multiple comparison test.

\section{Ethics approval and consent to participate}

All animal experiments were performed in accordance with the approved animal protocols and the guidelines of the Institutional Animal Care and Use Committee of Chungbuk National University (CBNUA-432-12-02).

\section{Consent for publication}

Not applicable.

\section{Conclusions}

These results indicate the roles of PAK1 in neuronal death and neurodegeneration induced by oxidative stress. Down-regulation of PAK1 activity was strongly correlated with cell death and loss of mesencephalic DA neurons. Conversely, up-regulation of PAK1 activity recovered loss of mesencephalic DA neurons and behavioral defects in a hemiparkinsonian animal model. Taken together, our data provided novel mechanisms in the pathogensis of PD and a useful therapeutic target.

\section{Availability of data and materials}

The datasets supporting the conclusions of this article are included within the article.

\section{Additional files}

Additional file 1: Figure S1. SH-SY5Y cells and HEK 293T cells expressed endogenous PAK1. The 10 or $20 \mu \mathrm{g}$ of lyastes from each cell line was separated on SDS-PAGE and subjected to Western blot analysis using anti-PAK1 antibody. The membrane was deprobed and reprobed by anti-GAPDH antibody. (TIF $2426 \mathrm{~kb}$ )

Additional file 2: Figure S2. Reduction of $\mathrm{BCl}-2$ level by 6-OHDA treatment is independent of transcription. a. SH-SY5Y cells were treated 50 $\mu \mathrm{M}$ 6-OHDA for $9 \mathrm{~h}$ and total RNA was isolated. Purified $3 \mu \mathrm{g}$ of total
RNA was used in RT-PCR analysis for $B C l-2, B C l-{ }_{-x}$, and GAPDH mRNA (w/o: negative control without $\mathrm{RT}$ reaction). b. Bar graphic representation of RT-PCR analysis. The intensity of $\mathrm{BCl}-2$ or $\mathrm{BCl}_{-x \mathrm{~L}}$ band at each time point was normalized by the intensity of GAPDH band, respectively. The data was presented a relative value to value of $0 \mathrm{~h}$. (TIF $163 \mathrm{~kb}$ )

Additional file 3: Figure S3. 6-OHDA treatment reduces phosphorylated PAK1 level in cultured DA neurons. a. Mesencephalic DA neurons were isolated from the ventral tegumental area (VTA) and cultured for 16 day before use. Cultured DA neurons were treated with $100 \mu \mathrm{M}$ 6-OHDA for $9 \mathrm{~h}$ and fixed. The cultures were immunostained with anti-monoclonal tyrosine hydroxylase antibody (TH-16, T2928, Sigma-Aldrich), anti-polyclonal PAK1 antibody (N-20, sc-882, SANTA CRUZ Biotechnology), or anti-phospho-PAK1 antibody (sc-21903-R, SANTA CRUZ Biotechnology). The cultures were subsequently immunostained with Alex Fluor 488 anti-mouse lgG antibody (A11029, Molecular Probes) for visualization of TH staining and Cy3-conjugated anti-rabbit IgG antibody (111-165-144, Jackson ImmunoResearch Lab) for PAK1 and P-PAK1 staining. Images were acquired by fluorescent microscopy (BX-51, Olympus) and analyzed by $\mathrm{NIH}$ image analysis program (ImageJ ver 1.47v). Scale bar: $20 \mu \mathrm{m}$. b. Bar graphic representation of image analysis. 6-OHDA treatment could not change PAK1 level (CTL: $100.0 \pm 7.40 \%$, $n=55$ neurons from 6 plates; 6-OHDA: $109.2 \pm 3.79 \%, n=56$ neurons from 6 plates, ns: not significant) but decreased p-PAK1 level (CTL: $100.0 \pm$ $5.56 \%, n=20$ neurons from 3 plates; $6-O H D A: 72.71 \pm 8.81 \%, n=27$ neurons from 3 plates, Student's $t$-tests: $\left.{ }^{*} P<0.05\right)($ TIF $10356 \mathrm{~kb}$ )

Additional file 4: Figure S4. PAK1-DN expression reduces the $\mathrm{BCl}-2$ level in HEK 293T cells. a. Lysates of HEK 293T cells transfected with GFP, PAK1-WT, PAK1-CA, or PAK1-DN vectors were subjected to Western blot analysis using Bcl-2 antibody. b. Quantification of Western blot analysis. Each band was normalized with the band intensity of WT (GFP: $101.0 \pm$ $5.19 \%, n=5$; WT: $100.0 \%, n=5$; CA: $95.9 \pm 6.46 \%, n=5$; DN: $73.16 \pm 6.87$ $\%, n=5$; One-way ANOVA, $F_{3,19}=5.909,{ }^{* *} P=0.0065$, Newman-Keuls multiple comparison test: ${ }^{* *} P<0.01,{ }^{*} P<0.5$ ). (TIF $2613 \mathrm{~kb}$ )

Additional file 5: Figure S5. Reduction of $\mathrm{BCl}-1$ by PAK-DN is independent of transcription. a. Total RNA was purified from SH-SY5Y cells expressing GFP, PAK1-CA, or PAK1-DN. And $3 \mu \mathrm{g}$ of total RNA from each was used for RT-PCR analysis using SuperScript III (Invitrogen). The PCR primers used in RT-PCR are follows; BCl-2 forward: 5'-agatgggaacactggtggag-3', Bcl-2 reverse: 5'-cttccccaaaagaaatgcaa-3', Bad forward: 5'-cctcaggcctatgcaaaaag-3', Bad reverse: 5'-taaacctggctcgcgactta-3', BCl- $\mathrm{x}_{\mathrm{L}}$ forward: 5'-ggctgggatacttttgtgga-3', BCl- $x_{L}$ reverse: 5'-gggagggtagagtggatggt-3', GAPDH forward: 5'-gagtcaacggtttggtcgt-3', GAPDH reverse: 5'-ttgattttggagggatctcg-3'. b. Bar graphic representation of RT-PCR analysis. Each band was normalized with intensity of GAPDH. (TIF 208 kb)

Additional file 6: Figure S6. Other mutants of PAK1- inactive form reduce $\mathrm{BCl}-2$ level. a. HEK cells were transfected with 1, 2, or $3 \mu \mathrm{g}$ of GFP, PAK1-WT, PAK1-H83,86L, or PAK1-K299R vectors and incubated for $48 \mathrm{~h}$. The cell lysates were subjected to Western blotting analysis using anti-Myc, BCl2, BCl- $x_{L}$, or GAPDH antibody. b. The autoinhibitory domain (AID) of hPAK1 (67-150 amino acids) were amplified by PCR methods (hPAk1-67-R1-S: 5'ggaattcggaagaaagagaaagagcggc-3', hPAK1-150-Xho-A: 5'-ccgctcgagttaagct gacttatctgtaaagc-3') and inserted to EcoRI/Xhol site of pCMV-Myc vector (Clontech) in-frame with Myc-tag, producing PAK1-DN (67-150) [47]. HEK cells were transfected with 1,2 , or $3 \mu \mathrm{g}$ of PAK1-DN (67-150) vector and cell lysates were analyzed by Western blotting assay. (TIF 278 kb)

Additional file 7: Figure S7. PAK1-CA expression rescues behavioral defect and loss of mesencephalic dopamine neurons induced by MPTP injection. a. Experimental scheme and procedure. b. Lentiviruses encoding GFP or PAK1-CA were infused into the right SNpc at rate of $0.5 \mu \mathrm{l} / \mathrm{min}$ at the following coordinates: anteroposterior, $-5.3 \mathrm{~mm}$ from the bregma; mediolateral, $-2.3 \mathrm{~mm}$; dorsoventral, $-7.3 \mathrm{~mm}$ below surface of the dura. A 2 $\mu$ dose of MPTP-HCl (1 $\mu$ M, 1-Methyl-4-phenyl-1,2,3,6-tetrahydropyridine hydrochloride, Sigma-Aldrich) was infused into the right striatum at a rate of $0.5 \mu \mathrm{l} / \mathrm{min}$ at the following coordinates: anteroposterior, $1.0 \mathrm{~mm}$ from the bregma; mediolateral, $-3.0 \mathrm{~mm}$; dorsoventral, $-5.0 \mathrm{~mm}$ below surface of the dura [48]. After 3 weeks, the midbrain tissue sections were immunostained with anti-Tyrosine Hyroxylase antibody and visualized by immunostaining using Cy3-conjugated goat anti-rabbit lgG antibody. c. The loss of DA neurons in the SNpc induced by MPTP injection was blocked by PAK1-CA expression, 
but not by GFP expression (GFP: $75.7 \pm 0.41 \%, n=3$, compared to the ipsilateral side; PAK1-CA: $101.4 \pm 2.71 \%, n=4$, compare to ipsilateral side, Student's $t$-tests, $\left.{ }^{* *} P<0.01\right)$. d. PAK1-CA expression significantly improved usage of the contralateral limb in a hemiparkinsonian animal model (GFP: PAK1-CA, pretest, $48.8 \pm 1.59, n=3: 52.8 \pm 1.92, n=4 ; 1$ week, $29.6 \pm 2.50, n=3$ : $44.03 \pm 5.18, n=4 ; 2$ weeks, $34.2 \pm 3.30, n=3: 48.30 \pm 2.58, n=4 ; 3$ weeks, $28.97 \pm 1.09, n=3: 45.75 \pm 2.15, n=4$; Two-way ANOVA, $F_{3,20}=1.746, P=0.19$, 1, Bonferroni multiple comparison tests, ${ }^{*} P<0.05,{ }^{* *} P<0.01$ ). (TIF $2786 \mathrm{~kb}$ )

\section{Abbreviations}

PAK1: p21-activated serine/threonine kinase 1; DN: dominant-negative form CA: constitutively active form; BCl-2: B-cell lymphoma 2; ERK: extracellular signal-regulated kinase; DA: dopamine; SN: substantia nigra; BCl-xL: B-cell lymphoma-extra large; Mcl-1: myeloid cell leukemia 1; Bad: BCl2-associated agonist of cell death; Bax: Bcl2-associated X protein; Bak: Bcl-2 homologous antagonist/killer; Bok: Bcl-2 related ovarian killer; Bid: Bcl-2 interacting domain; IL3: interleukin 3; AD: Alzheimer's disease; HD: huntington's disease; Rac: Ras-related C3 botulinum toxin substrate; PD: parkinson's disease; RTPCR: reverse transcription-polymerase chain reaction, MAPK, mitogenactivated protein kinase; co-IP: co-immunoprecipitation; 6-OHDA: 6hydroxydopamine; PP: phosphatase; TH: tyrosine hydroxylase; SNpc: substantia nigra pars compacta; POPX1: partner of pix 1; HEK: human embryonic kidney; VTA: ventral tegmental area; CFP: cyan fluorescent protein; TUNEL: terminal deoxynucleotidyl transferase dUTP nick end labeling; OCT: optimum cutting temperature; Cy3: cyanine 3; BSA: bovine serum albumin; CCD: charge-coupled device; TMR: tetramethylrhodamine; SDSPAGE: sodium dodecyl sulfate polyacrylamide gel electrophoresis; PVDF: polyvinylidene fluoride; SEM: standard error of the mean; ANOVA: analysis of variance; MPTP: 1-Methyl-4-phenyl-1,2,3,6tetrahydropyridine.

\section{Competing interests}

The authors declare that they have no competing interests.

\section{Authors' contributions}

H.K.K. conceptualized the research and designed the experiments; H.K. produced lentivirus and performed stereotactic neurosurgery and behavioral experiments; Y.-J.N. performed cell viability analysis; J.-Y.O., Y.-J.N. performed analysis of the $\mathrm{BCl}-2$ level induced by PAK1-DN expression; A.J., A.K. performed PAK1 phosphorylation analysis; H.K., Y.-J.N. performed phosphatase analysis; H.K.K., E.-G.K., S.-L.C., E.-Y.S. analyzed the data and discussed the results; H.K.K. wrote the manuscript. All authors read and approved the final manuscript.

\section{Funding}

This research was supported by Basic Science Research Program through the National Research Foundation of Korea (NRF) funded by the Ministry of Science, ICT and Future Planning (NRF-2010-0006967).

\section{Author details}

'Department of Medicine and Microbiology, College of Medicine, Signaling Disorder Research Center, Chungbuk National University, Cheongju 28644, The Republic of Korea. ${ }^{2}$ Department of Medicine and Biochemistry, College of Medicine, Signaling Disorder Research Center, Chungbuk National University, Cheongju 28644, The Republic of Korea. ${ }^{3}$ Department of Medicine and Microbiology, College of Medicine, Chungbuk National University, Chungdae-ro 1, Seowon-gu, Cheongju 28644, The Republic of Korea.

\section{Received: 24 February 2016 Accepted: 21 April 2016}

Published online: 27 April 2016

\section{References}

1. Kumar A, Molli PR, Pakala SB, Bui Nguyen TM, Rayala SK, Kumar R. PAK thread from amoeba to mammals. J Cell Biochem. 2009;107(4):579-85.

2. Vadlamudi RK, Kumar R. P21-activated kinases in human cancer. Cancer Metastasis Rev. 2003;22(4):385-93.

3. Molli PR, Li DQ, Murray BW, Rayala SK, Kumar R. PAK signaling in oncogenesis. Oncogene. 2009;28(28):2545-55.

4. Kumar R, Gururaj AE, Barnes CJ. p21-activated kinases in cancer. Nat Rev Cancer. 2006;6(6):459-71.
5. Dummler B, Ohshiro K, Kumar R, Field J. Pak protein kinases and their role in cancer. Cancer Metastasis Rev. 2009;28(1-2):51-63.

6. Aoki H, Yokoyama T, Fujiwara K, Tari AM, Sawaya R, Suki D, Hess KR, Aldape KD, Kondo S, Kumar R, Kondo Y. Phosphorylated Pak1 level in the cytoplasm correlates with shorter survival time in patients with glioblastoma. Clin Cancer Res. 2007;13(22 Pt 1):6603-9.

7. Cory S, Huang DC, Adams JM. The BCl-2 family: roles in cell survival and oncogenesis. Oncogene. 2003;22(53):8590-607.

8. Golstein P. Controlling cell death. Science. 1997;275(5303):1081-2.

9. Adams JM, Cory S. The Bcl-2 protein family: arbiters of cell survival. Science. 1998;281(5381):1322-6.

10. Jin S, Zhuo Y, Guo W, Field J. p21-activated Kinase 1 (Pak1)-dependent phosphorylation of Raf-1 regulates its mitochondrial localization, phosphorylation of BAD, and BCl-2 association. J Biol Chem. 2005;280(26): 24698-705.

11. Schurmann A, Mooney AF, Sanders LC, Sells MA, Wang HG, Reed JC, Bokoch GM. p21-activated kinase 1 phosphorylates the death agonist bad and protects cells from apoptosis. Mol Cell Biol. 2000;20(2):453-61.

12. Ma QL, Yang F, Frautschy SA, Cole GM. PAK in Alzheimer disease, Huntington disease and X-linked mental retardation. Cell Logist. 2012;2(2):117-25.

13. Zhao L, Ma QL, Calon F, Harris-White ME, Yang F, Lim GP, Morihara T, Ubeda OJ, Ambegaokar S, Hansen JE, Weisbart RH, Teter B, Frautschy SA, Cole GM. Role of p21-activated kinase pathway defects in the cognitive deficits of Alzheimer disease. Nat Neurosci. 2006;9(2):234-42.

14. Luo S, Mizuta H, Rubinsztein DC. p21-activated kinase 1 promotes soluble mutant huntingtin self-interaction and enhances toxicity. Hum Mol Genet. 2008;17(6):895-905.

15. Chen LY, Rex CS, Babayan AH, Kramar EA, Lynch G, Gall CM, Lauterborn JC. Physiological activation of synaptic Rac > PAK ( $p-21$ activated kinase) signaling is defective in a mouse model of fragile $X$ syndrome. J Neurosci. 2010;30(33):10977-84.

16. Pan X, Chang X, Leung C, Zhou Z, Cao F, Xie W, Jia Z. PAK1 regulates cortical development via promoting neuronal migration and progenitor cell proliferation. Mol Brain. 2015;8:36.

17. Tabares-Seisdedos R, Dumont N, Baudot A, Valderas JM, Climent J, Valencia A, Crespo-Facorro B, Vieta E, Gomez-Beneyto M, Martinez S, Rubenstein JL. No paradox, no progress: inverse cancer comorbidity in people with other complex diseases. Lancet Oncol. 2011;12(6):604-8.

18. Morris $L G$, Veeriah $S$, Chan TA. Genetic determinants at the interface of cancer and neurodegenerative disease. Oncogene. 2010;29(24):3453-64.

19. Tang Y, Zhou H, Chen A, Pittman RN, Field J. The Akt proto-oncogene links Ras to Pak and cell survival signals. J Biol Chem. 2000;275(13):9106-9.

20. Vadlamudi RK, Adam L, Wang RA, Mandal M, Nguyen D, Sahin A, Chernoff J, Hung MC, Kumar R. Regulatable expression of p21-activated kinase-1 promotes anchorage-independent growth and abnormal organization of mitotic spindles in human epithelial breast cancer cells. J Biol Chem. 2000;275(46):36238-44.

21. Ogawa N, Tanaka K-i: Cyclosporin-Mediated Amelioration of Degeneration of Dopaminergic Neurons in Experimental Models of Parkinsonism. In: Immunosuppressant Analogs in Neuroprotection. edn.: Springer; 2003. p.35-48.

22. Dimmeler S, Breitschopf K, Haendeler J, Zeiher AM. Dephosphorylation targets $\mathrm{BCl}-2$ for ubiquitin-dependent degradation: a link between the apoptosome and the proteasome pathway. J Exp Med. 1999;189(11):1815-22.

23. Breitschopf K, Haendeler J, Malchow P, Zeiher AM, Dimmeler S. Posttranslational modification of $\mathrm{BCl}-2$ facilitates its proteasome-dependent degradation: molecular characterization of the involved signaling pathway. Mol Cell Biol. 2000;20(5):1886-96.

24. Xue Y, Ren J, Gao X, Jin C, Wen L, Yao X. GPS 2.0, a tool to predict kinase-specific phosphorylation sites in hierarchy. Mol Cell Proteomics. 2008;7(9):1598-608.

25. Deumens R, Blokland A, Prickaerts J. Modeling Parkinson's disease in rats: an evaluation of 6-OHDA lesions of the nigrostriatal pathway. Exp Neurol. 2002; 175(2):303-17.

26. Heikkila R, Sonsalla P, Duvoisin R. Biochemical models of Parkinson's disease. In: Drugs as Tools in Neurotransmitter Research. Springer; 1989. p. 351-84.

27. Harms AS, Barnum CJ, Ruhn KA, Varghese S, Trevino I, Blesch A, Tansey MG. Delayed dominant-negative TNF gene therapy halts progressive loss of nigral dopaminergic neurons in a rat model of Parkinson's disease. Mol Ther. 2011;19(1):46-52.

28. McCoy MK, Ruhn KA, Martinez TN, McAlpine FE, Blesch A, Tansey MG. Intranigral lentiviral delivery of dominant-negative TNF attenuates neurodegeneration and behavioral deficits in hemiparkinsonian rats. Mol Ther. 2008;16(9):1572-9. 
29. Meredith GE, Kang UJ. Behavioral models of Parkinson's disease in rodents: a new look at an old problem. Mov Disord. 2006;21(10):1595-606.

30. Tillerson JL, Cohen AD, Philhower J, Miller GW, Zigmond MJ, Schallert T. Forced limb-use effects on the behavioral and neurochemical effects of 6-hydroxydopamine. J Neurosci. 2001;21(12):4427-35.

31. Tatton WG, Chalmers-Redman R, Brown D, Tatton N. Apoptosis in Parkinson's disease: signals for neuronal degradation. Ann Neurol. 2003; 53(3):S61-70. discussion S-2.

32. Tatton NA. Increased caspase 3 and Bax immunoreactivity accompany nuclear GAPDH translocation and neuronal apoptosis in Parkinson's disease. Exp Neurol. 2000;166(1):29-43.

33. Hartmann A, Michel PP, Troadec JD, Mouatt-Prigent A, Faucheux BA, Ruberg M, Agid Y, Hirsch EC. Is Bax a mitochondrial mediator in apoptotic death of dopaminergic neurons in Parkinson's disease? J Neurochem. 2001;76(6):1785-93.

34. McNaught KS, Olanow CW. Protein aggregation in the pathogenesis of familial and sporadic Parkinson's disease. Neurobiol Aging. 2006;27(4):530-45.

35. Keller JN, Hanni KB, Markesbery WR. Possible involvement of proteasome inhibition in aging: implications for oxidative stress. Mech Ageing Dev. 2000; 113(1):61-70.

36. Zeng BY, Medhurst AD, Jackson M, Rose $\mathrm{S}$, Jenner P. Proteasomal activity in brain differs between species and brain regions and changes with age. Mech Ageing Dev. 2005;126(6-7):760-6

37. Westphal RS, Coffee Jr RL, Marotta A, Pelech SL, Wadzinski BE. Identification of kinase-phosphatase signaling modules composed of p70 S6 kinaseprotein phosphatase 2A (PP2A) and p21-activated kinase-PP2A. J Biol Chem. 1999;274(2):687-92.

38. Zhan Q, Ge Q, Ohira T, Van Dyke T, Badwey JA. p21-activated kinase 2 in neutrophils can be regulated by phosphorylation at multiple sites and by a variety of protein phosphatases. J Immunol. 2003;171(7):3785-93.

39. Koh CG, Tan EJ, Manser E, Lim L. The p21-activated kinase PAK is negatively regulated by $P O P X 1$ and $P O P X 2$, a pair of serine/threonine phosphatases of the PP2C family. Curr Biol. 2002;12(4):317-21.

40. Chan PM, Lim L, Manser E. PAK is regulated by PI3K, PIX, CDC42, and PP2Calpha and mediates focal adhesion turnover in the hyperosmotic stress-induced p38 pathway. J Biol Chem. 2008;283(36):24949-61.

41. Albensi BC, Sullivan PG, Thompson MB, Scheff SW, Mattson MP. Cyclosporin ameliorates traumatic brain-injury-induced alterations of hippocampal synaptic plasticity. Exp Neurol. 2000;162(2):385-9.

42. Sullivan PG, Thompson M, Scheff SW. Continuous infusion of cyclosporin A postinjury significantly ameliorates cortical damage following traumatic brain injury. Exp Neurol. 2000;161(2):631-7.

43. Fasano C, Thibault D, Trudeau LE. Culture of postnatal mesencephalic dopamine neurons on an astrocyte monolayer. Curr Protoc Neurosci. 2008;3:3-21.

44. Adam L, Vadlamudi R, Mandal M, Chernoff J, Kumar R. Regulation of microfilament reorganization and invasiveness of breast cancer cells by kinase dead p21-activated kinase-1. J Biol Chem. 2000;275(16):12041-50.

45. Salmon P, Kindler V, Ducrey O, Chapuis B, Zubler RH, Trono D. High-level transgene expression in human hematopoietic progenitors and differentiated blood lineages after transduction with improved lentiviral vectors. Blood. 2000;96(10):3392-8.

46. Jeong JH, Nam YJ, Kim SY, Kim EG, Jeong J, Kim HK. The transport of Staufen2-containing ribonucleoprotein complexes involves kinesin motor protein and is modulated by mitogen-activated protein kinase pathway. J Neurochem. 2007;102(6):2073-84

47. Hayashi ML, Choi SY, Rao BS, Jung HY, Lee HK, Zhang D, Chattarji S, Kirkwood A, Tonegawa S. Altered cortical synaptic morphology and impaired memory consolidation in forebrain- specific dominant-negative PAK transgenic mice. Neuron. 2004:42(5):773-87.

48. Ho SC, Hsu CC, Pawlak CR, Tikhonova MA, Lai TJ, Amstislavskaya TG, Ho YJ. Effects of ceftriaxone on the behavioral and neuronal changes in an MPTPinduced Parkinson's disease rat model. Behav Brain Res. 2014;268:177-84.

\section{Submit your next manuscript to BioMed Central and we will help you at every step:}

- We accept pre-submission inquiries

- Our selector tool helps you to find the most relevant journal

- We provide round the clock customer support

- Convenient online submission

- Thorough peer review

- Inclusion in PubMed and all major indexing services

- Maximum visibility for your research

Submit your manuscript at www.biomedcentral.com/submit
Biomed Central 